\title{
Tobacco-Associated Carcinogen
}

National Cancer Institute

\section{Source}

National Cancer Institute. Tobacco-Associated Carcinogen. NCI Thesaurus. Code C1956.

A chemical that is present in tobacco products, including pipe, cigarette and cigar as well as chewing tobacco and snuff, or that is produced during the burning of tobacco and causes a carcinogenic effect in humans. 